\title{
Critical Review of Mineral Resource Classification Techniques in the Gold Mining Industry
}

\author{
SKA Owusu* and K Dagdelen \\ Department of Mining Engineering, Colorado School of Mines, Colorado, USA
}

Submission: October 09, 2019; Published: October 21, 2019

*Corresponding author: SKA Owusu, Department of Mining Engineering, Colorado School of Mines, Colorado, USA

\begin{abstract}
This paper investigates the different classification techniques used by the gold mining industry professionals to classify mineral resources into measured, indicated and inferred categories. The research is based on forty-five (45) public disclosure reports from System for Electronic Document Analysis and Retrieval (SEDAR) and one general classification guideline of a major gold producer unlisted on SEDAR. The survey includes public documents categorized by various geologic types of deposits and companies considered as major, mid-tier and junior gold mining operators. It encompasses 19 NI 43-101 technical reports filed in 2018 and 26 reports filed between 2006 and 2017. The purpose of the research is to explore and understand how the different mining companies perform classification of mineral resources in terms of the requirements used and different deposit type consideration. The paper summarizes the survey results, discusses the general implications and the need for developing more formal approach to mineral resource classification.
\end{abstract}

Keywords: Mine designs; Mineral resources; Geometric techniques; Geostatistical techniques; Ellipsoidal search; Drill holes; Octant search

\section{Introduction}

\section{Purpose of the Study}

Capital-intensive investment decisions are made in the mining industry with respect to confidence levels displayed in the mineral resources and reserves. The quality and quantity of materials estimated to be mined from a deposit have economic implications on the production schedule. The uncertainties with regards to the composition of a deposit may result in unreliable estimates and misclassification of resources. Although the various industry mineral resource reporting standard codes provide guidelines to be followed in generating classification reports, different mining companies use various procedures because each Competent Person (CP) or Qualified Person (QP) uses different assumptions, since none of the codes provides consistent assumptions to be adopted for reporting purposes. This has created classification categorization inconsistencies, leading to the disclosure of mineral resource reports with different accuracies in the industry. Mineral re-source classification is a key requirement for public reporting of economic assessment and investor confidence in a mineral project.

\section{Mineral Resource Definitions and Standards}

To protect investors and mineral project advisors from misleading public disclosure of mineral resources, the Council of Mining and Metallurgical Institutes (CMMI) introduced classification standard codes in 1994 to provide guidelines to cate gorize mineral resources into measured, indicated and inferred classes in decreasing order of geological confidence reposed in the blocks in a deposit. The authenticity of the available data for estimation and classification determines the geological confidence assigned by the CP or QP. The main factors that are evaluated to justify the credibility of a data include nature, quality, quantity and distribution. The distribution of most earth science data is skewed or lognormal. Effective and credible resource estimation and classification lead to reliable mine designs, production schedules, robust business plans and financial forecasts. Forty-five (45) different public disclosure reports on System for Electronic Document Analysis and Retrieval (SEDAR) (www. sedar.com) were reviewed with respect to gold mining companies considered as major, mid-tier and junior categories. The survey covered 20 junior, 20 mid-tier, and 5 major companies in North America, South America, Asia, and Africa. The Council of Mining and Metallurgical Institutes (CMMI) in 1994, formed a working group of representatives from different organizations to standardize mineral resource definitions. In 2000, the committee became the Combined Reserves International Reporting Standards Commit-tee (CRIRSCO) and introduced a concept that Measured and Indicated mineral resources had to support mine planning. The main reporting codes produced by the member CRIRSCO institutions are the Canadian National Instrument 43-101 (NI 43-101) Code, the Australasian Joint Ore Re-serves 
Committee (JORC) Code, the South African Mineral Resource Committee (SAMREC) Code and the American Society for Mining, Metallurgy and Exploration (SME) Guide, 2007. Other reporting codes include the Europe and United Kingdom (PERC) Code, the Brazil (CBRR) Guide, Chile and Peru (CMC) Guide, the Kazakhstan (KAZRC) Guide, the Mongolia (MRC) Code, and the Russia (NAEN) Code. The common goal of the various standard reporting codes is to ensure competence, materiality and transparency [1]. The principle of competence unreservedly assumes that the estimation and classification are done correctly, according to the current accepted practice. The transparency requires that the information contained in a public report should be accurate and enough. The materiality requires that all the relevant information needed by investors and their professional advisors to enable them to make informed business decisions should be contained in the public report. However, none of the standard codes specifies the consistent procedures to be followed by QPS in ensuring these three key inputs are included in public reporting of mineral resources.

\section{System for Electronic Document Analysis and Retriev- al (SEDAR)}

SEDAR is an official webpage developed by the Canadian Securities Administrators to provide access to most public securities documents and information. The statutory objective of the webpage is to enhance investor awareness of the respective business and to promote confidence in the transparent operation of capital markets in Canada. The Canadian Institute of Mining Definition Standards on Mineral Resources and Reserves (CIM Definition Standards) established the guidance on the definitions for mineral resources, mineral reserves, and mining studies used in Canada. The Canadian Securities Administrators (CSA) developed the NI 43-101 reporting code and it came into force in 2001. The code was established to provide best practice standards and guidelines for public disclosure of mineral resources and reserves reports in Canada. It was amended in 2005, 2011 and 2014. The NI 43-101 reporting code focuses on improving the standards of practicing governing operating activities and the need for good public disclosure. It provides some specific requirements for reporting mineral resource estimates and classification to meet standard public disclosure. The guideline enforces the QPs to provide information that are comprehensive in their technical re-ports on exploration information, mineral resources and mineral reserves. However, the guideline is not prescriptive in terms of geological details, as the quantity of geological information needed to categorize mineral resources were not provided. The quality of reports varies as industry practices and assumptions considered by various QPs differ. Currently, there is no one document that specifies the acceptable industry practice and assumption to be followed by all QPs. Considering same mineral deposit, different QPs employ different assumptions and techniques to generate the estimation and classification with the same project drilling data. At each stage of the estimation process, different expertise skills are applied. Due to different approaches used by different industry professionals to analyze and interpret geologic data, there are various misleading public reports in the mining industry. The definition of each classification category can be found on www.cim.org

\section{Classification Methods}

Mineral resource classification is important to mining companies, investors, and financial institutions, as investment decisions are usually based on grade, tonnage and confidence assigned to deposits. However, the approach used to perform classification remains subjective because of lack of formal standards. The various public reporting codes do not categorically recommend the method or threshold needed to be used for classification, as the process depends on the judgement of the responsible CP or QP. The industry's best practice for classification is assessing and quantifying the uncertainty and risk associated with mineral resource estimation. The two-basic methods used to perform classification tasks are the geometric and geostatistical techniques. In the survey, the geometric classification method was discovered to be mostly used in the mineral industry. Classification is commonly performed on a block-by-block basis, but the volumes are chosen reasonably large and contiguous, because one often believes that confidence in the grade should not change abruptly between adjacent blocks [2].

\section{Geometric Methods}

The geometric methods of mineral resource classification consider the amount, proximity and location of data available for estimation of a block. In the review of the recent classification reports, the geometric information used by the industry professionals included the dimensions of ellipsoidal search (ES), number of drill holes (NDH), minimum number of samples per estimate (NS), distance to nearest drill hole (DNDH), average drill hole spacing (DHS), and de-clustering by octant search (OS). The survey of the classification reports showed that each QP unilaterally selected the information to be considered in assigning confidence levels to blocks, as there are no standards to determine the needed information to be used for a deposit. The quantity of information to be used for classification is unrestricted, hence various QPs in the industry make different assumptions in assigning parameters to define the classification categories. Considering the minimum distance between a block's centroid and the composite samples for estimation, some QPs assigned different percentages of the variogram sill range while others assumed different values, based on their understanding of the deposits. Examples of the different assumptions made by the QPs in the reviewed technical reports can be found in the survey results in the next section. Generally, the geometric classification method does not consider the spatial continuity of the data in characterizing uncertainty associated with the estimation of the grades. 


\section{Geostatistical Methods}

The geostatistical classification methods are used to quantify risk on a given future production period. It is an effective and efficient method used to model geologic and grade uncertainty in mineral deposits. According to Deutsch et al. [2], desire to have purely probabilistic criteria based on sound estimates of uncertainty are understandable. The probabilistic techniques rely on classifying the blocks either by using KV directly or characterizing uncertainty of grade estimates, tonnages, and quantity of metals based on confidence intervals, kriging variance, and/or conditionally simulated realization of grades. After reviewing the recent NI 43-101 public reports, it was evident that the industry players have not embraced the geostatistical techniques. Although it makes sense, characterizing uncertainty of grade estimates, tonnages and quantity of metals based on confidence intervals, kriging variance and/or conditionally simulated realization of grades were applied by only few companies in the mining industry.

\section{Kriging Variance Approach}

Kriging is a minimum variance estimator which minimizes the squared error between the estimated value and the unknown true value. The error variance generated from the estimation is the kriging variance (KV). The KV considers geostatistical parameters which combine both geometric and geological inputs in characterizing the uncertainty associated with the estimated parameter. The consideration of the spatial structure of the estimated variable and the redundancy between samples are the purposes of using kriging variance as the criterion for classification. In the process of assigning confidence levels, estimated blocks with high kriging variance have lower confidence than those with lower kriging variance. Emery et al. [3] suggest the establishment of KV thresholds for measured, indicated and inferred mineral resources classification categories based on a given desired number of drill holes, spacing and the variogram model in each domain. Classifying each block into a specific measured, indicated and inferred mineral resource category is done based on KVs associated with each block and these previously determined thresholds.

\section{Classification Based on $\mathbf{9 0 \%}$ Confidence Interval}

This technique involves calculating the $90 \%$ confidence intervals (CI) on the tonnage, grade and metal content within quarterly and annual production blocks either through KV or geostatistical conditional simulations. A recognized mining industry practice in the application of this technique is the ability to determine the drill hole spacing to be enough in the prediction of tonnage, grade and metal content within $\pm 15 \%$ relative precision at $90 \%$ confidence interval within a quarterly or annual production rates. Measured resource considers quarterly production period and indicated resource corresponds to annual production period. For the detail description of mineral resource classification based on $90 \%$ confidence intervals, please refer to Verly et al. [4].
Survey Results and Discussions

\section{Survey Details}

Table 1: Number of technical reports by continent, country and company category.

\begin{tabular}{|c|c|c|}
\hline Continent & Count & Percentage \\
\hline North America & 27 & 60 \\
\hline South America & 11 & 24.4 \\
\hline Africa & 6 & 13.3 \\
\hline Asia & 1 & 2.2 \\
\hline Country & Count & Percentage \\
\hline United States & 16 & 35.6 \\
\hline Canada & 11 & 24.4 \\
\hline Mauritania & 5 & 11.1 \\
\hline Chile & 4 & 8.9 \\
\hline Mexico & 2 & 4.4 \\
\hline Brazil & 2 & 4.4 \\
\hline Argentina & 1 & 2.2 \\
\hline Burkina Faso & 1 & 2.2 \\
\hline Dominican Republic & 1 & 2.2 \\
\hline Guyana & 1 & 2.2 \\
\hline Mongolia & 1 & 2.2 \\
\hline & & 43.5 \\
\hline Company Category & Count & Percentage \\
\hline Major & 6 & 13 \\
\hline Mid-tier & 20 & \\
\hline Junior & 20 & \\
\hline
\end{tabular}

This paper focuses on the review of 45 NI 34-101 technical reports of gold deposits which were obtained from System for Electronic Document Analysis and Retrieval (SEDAR) website plus one major gold mining company's publicly available general classification guidelines. The purpose of the survey was to investigate the current different techniques used to classify gold deposits into measured, indicated and inferred categories. After evaluating the different reports, it was realized that the mineral industry players use different procedures to categorize blocks into different classes, confirming irregular methodology used in the classification of mineral resources. A summary table was created to include the following information as formally described in the various NI 43-101 reports: publication date, company name, location, continent, state or province, commodity type, operation type, deposit type, interpolation method, classification criteria, classification technique, specific gravity method, domaining and boundary applications. The public disclosure reports were grouped with respect to companies considered as major, mid-tier and junior gold mining operators. The investigations covered twenty (20) junior, twenty (20) mid-tier, and five (5) major gold mining companies in North America, South America, Asia and Africa. Also, the general classification guidelines of a major gold mining company unlisted on SEDAR was reviewed. 
Tables 1-4 show details of the number of NI 43-101 reports that were surveyed in terms of continent, country, company category, company name, deposit type and operation type. The overall investigations were based on; classification reports for same deposit type for same company, classification reports for same deposit type for different companies, classification reports from different consultants on same deposit type for different companies, and different classification estimation passes for same mining district and mineralized belt. After critical look at the classification guidelines used by the various companies from SEDAR, forty-three (43) of the reports applied geometric methods and two (2) applied combined geostatistical and geometric methods. The major gold mining company unlisted on SEDAR also applied both geostatistical and geometric techniques. The abbreviations used in the tables are; Drill Hole Spacing (DHS), Distance to Nearest Drill Hole (DNDH), Number of Samples (NS), Number of Drill Holes (NDH), Ellipsoidal Search (ES), Octant Search (OS), Drill Hole Intercept (DH Intercept), and Kriging Variance (KV) (Table 1).

Table 2: Number of technical reports by deposit type and operation type.

\begin{tabular}{|c|c|c|}
\hline Deposit Type & Count & Percentage \\
\hline Greenstone Belt, Orogenic & 16 & 35.6 \\
\hline Gold-Copper Porphyry & 6 & 13.3 \\
\hline Epithermal Low Sulfidation & 9 & 20 \\
\hline Carlin-Type & 4 & 8.9 \\
\hline Lode and Placer & 4 & 8.9 \\
\hline Gold Porphyry & 2 & 4.4 \\
\hline Epithermal High Sulfidation & 2 & 4.4 \\
\hline Placer Gold & 1 & 2.2 \\
\hline Breccia Pipe & 1 & 2.2 \\
\hline & & \\
\hline Operations Type & Count & Percentage \\
\hline Surface & 29 & 64.4 \\
\hline Underground & 8 & 17.8 \\
\hline Surface and Underground & 7 & 15.6 \\
\hline Unknown & 1 & 2.2 \\
\hline
\end{tabular}

Generally, the parameters used differed even in the case of same type of deposit. For example, using the variogram range as a measure of search neighborhood, companies used different per-centages of the variogram range, for example, 95\%, 90\%, $80 \%$, etc. After critical study of the table and realizing different parameters used, one can conclude that different assumptions made by different QPs lead to potential discrepancies in public reporting of mineral resources. A gold deposit categorized by QP-A as measured may not pass the classification test for inferred by QP-B. In the public domain, it is difficult for investors to justify the correct reports from the misleading ones. The current industry practices lack consistency, resulting in various forms of implications, hence the need for the development of more formal methods (Tables 2-4).
Table 3: Number of technical reports per each gold mining company.

\begin{tabular}{|c|c|c|}
\hline Company & Count & Percentage \\
\hline Kinross Gold & 16 & 34.8 \\
\hline Barrick Gold & 6 & 13 \\
\hline Coeur Mining & 3 & 6.5 \\
\hline New Gold & 3 & 6.5 \\
\hline Centerra Gold & 2 & 4.3 \\
\hline Osisko Mining & 2 & 4.3 \\
\hline Agnico Eagle & 1 & 2.2 \\
\hline Allegiate Gold & 1 & 2.2 \\
\hline Brigus Gold & 1 & 2.2 \\
\hline Goldcorp Mining & 1 & 2.2 \\
\hline Guyana Goldfields & 1 & 2.2 \\
\hline Parallel Mining & 1 & 2.2 \\
\hline Wallbridge Mining & 1 & 2.2 \\
\hline Newmont Gold & 1 & 2.2 \\
\hline
\end{tabular}

Table 4: Different classification techniques applied in the technical reports.

\begin{tabular}{|c|c|c|}
\hline Classification Technique & Count & Percentage \\
\hline DHS & 2 & 4.4 \\
\hline DNDH & 2 & 4.4 \\
\hline NDH & 0 & 0 \\
\hline NS + DNDH & 2 & 4.4 \\
\hline DHS + NDH & 3 & 6.7 \\
\hline NDH + ES & 1 & 2.2 \\
\hline NDH + NS & 2 & 4.4 \\
\hline NS + ES & 3 & 6.7 \\
\hline NS + OS & 3 & 6.7 \\
\hline DHS + DNDH & 1 & 2.2 \\
\hline NDH + DNDH & 4 & 8.9 \\
\hline DHS + NDH + DNDH & 1 & 2.2 \\
\hline DHS + NS + OS & 1 & 2.2 \\
\hline NDH + DNDH + ES & 2 & 4.4 \\
\hline NDH + NS + DNDH & 5 & 11.1 \\
\hline NDH + NS + OS & 1 & 2.2 \\
\hline DH Intercept + NS & 6 & 13.3 \\
\hline KV+DNDH+NDH +NS & 2 & 4.4 \\
\hline Unknown & 2 & 4.4 \\
\hline
\end{tabular}

\section{Geostatistical Techniques Applied in the Reports}

Although geostatistical methods are considered to be providing the best techniques available to model geologic and grade uncertainty in mineral deposits, it is evident from the survey and from Table 5, that the industry professionals do not commonly use these methods and even when they are used, the geostatistical methods also include assumptions on geometric parameters. 


\section{Insights in Mining Science \& Technology}

Table 5: Geostatistical with Geometric classification parameters applied to different deposits.

\begin{tabular}{|c|c|c|c|c|}
\hline Deposit Type & Parameter & Measured & Indicated & Inferred \\
\hline \multirow{5}{*}{ Gold-Copper Porphyry } & KV & & $\leq 0.66$ & $\geq 0.66$ \\
\hline & OS & & & \\
\hline & DNDH & $\leq 1 / 2$ sill range & $\leq 3 / 4$ sill range & $\leq$ sill range \\
\hline & $\mathrm{NDH}$ & $\geq 3$ & $\geq 3$ & \\
\hline & NS & $\geq 8$ & $\geq 8$ & $\geq 5$ \\
\hline \multirow{5}{*}{ Orogenic Gold Deposit } & KV & & $\leq 10$ & $\geq 10$ \\
\hline & OS & $\geq 3$ & $\geq 2$ & $\geq 1$ \\
\hline & DNDH & $\leq 1 / 2$ sill range & & \\
\hline & $\mathrm{NDH}$ & & & \\
\hline & NS & $\geq 12$ & $\geq 8$ & $\geq 4$ \\
\hline \multirow{6}{*}{$\begin{array}{l}\text { All Deposits (Major gold company unlisted } \\
\text { on SEDAR) }\end{array}$} & $\mathrm{NS} / \mathrm{H}$ & $\leq 1$ & $\leq 1$ & $\leq 1$ \\
\hline & DNDH & 2-3 times drill spacing & 2-3 times drill spacing & 2-3 times drill spacing \\
\hline & $\mathrm{NDH}$ & $\geq 3$ & $\geq 3$ & $\geq 3$ \\
\hline & NS & $\geq 3$ & $\geq 3$ & $\geq 3$ \\
\hline & \% Est. Error & $\pm 15 \%$ & $\pm 15 \%$ & $\pm 30 \%$ \\
\hline & \%Confidence & $\begin{array}{l}90 \% \text { over quarterly } \\
\text { period }\end{array}$ & $90 \%$ over annual period & $90 \%$ over annual period \\
\hline
\end{tabular}

\section{Geometric Techniques Applied in the Reports}

Considering the details of the survey, no single technique was considered for a specific type of deposit, as the various project QPs made different assumptions for same type of deposits.
Most of the companies used different classification parameters or requirements for similar type of deposit in different locations, as shown in Table 6. From the survey on the technical reports, only two companies followed a consistent classification method for all its deposits, regardless of the jurisdiction.

Table 6: Geometric classification parameters applied to different deposit types.

\begin{tabular}{|c|c|c|c|c|}
\hline Deposit Type & Parameter & Measured & Indicated & Inferred \\
\hline \multirow{3}{*}{ Breccia Pipe } & DHS & & & \\
\hline & DNDH & $\leq 55$ & $\leq 110$ & $\leq 200$ \\
\hline & $\mathrm{NDH}$ & $\geq 3$ & $\geq 1$ & $\geq 1$ \\
\hline \multirow{5}{*}{ Carlin-Type } & DHS & $\leq 35 \mathrm{ft}$ & $\leq 75 \mathrm{ft}$ & $\leq 150 \mathrm{ft}$ \\
\hline & DNDH & $\leq 30 \mathrm{ft}, 80 \%$ sill range & $\leq 80 \%-90 \%$ sill range & $\leq 90 \%$ sill range \\
\hline & NDH & $\geq 2$ & $\geq 1-2$ & $\geq 1-2$ \\
\hline & NS & $\geq 2-3$, with intercept & $\geq 1-2$ & $\geq 1-2$ \\
\hline & ES & & $\leq 80 \%$ sill range & $\leq 90 \%$ sill range \\
\hline \multirow{5}{*}{$\begin{array}{l}\text { Epithermal High } \\
\text { Sulfidation }\end{array}$} & DHS & & & \\
\hline & DNDH & & $\leq 20 \mathrm{~m}-35, \leq 40 \mathrm{~m}-70$ & $\leq 23 m-65, \leq 70 m-110, \leq 180 m$ \\
\hline & $\mathrm{NDH}$ & $\geq 1-2$ & $\geq 1-2$ & $\geq 1-2$ \\
\hline & NS & $\geq 1$, with intercept & $\geq 1-2$ & $\geq 1-2$ \\
\hline & ES & & & \\
\hline \multirow{5}{*}{$\begin{array}{l}\text { Epithermal Low } \\
\text { Sulfidation }\end{array}$} & DHS & $\leq 75 \mathrm{ft}$ & $\leq 200 \mathrm{ft}$ & $\leq 300 \mathrm{ft}$ \\
\hline & DNDH & $\leq 50 \mathrm{ft}, \leq 95 \mathrm{ft}, 70 \%$ sill range & $\leq 135 \mathrm{ft}, \leq 140 \mathrm{ft}, 80 \%$ sill range & $\leq 300 \mathrm{ft}, 95 \%$ sill range \\
\hline & $\mathrm{NDH}$ & $\geq 3-5$ & $\geq 2-3$ & $\geq 1-2$ \\
\hline & NS & $\geq 4-8, \leq 9-15$ & $\geq 3-6, \leq 7-12$ & $\geq 1-5, \leq 7-15$ \\
\hline & ES & $\leq 40 \mathrm{ft}$ & $\leq 100 \mathrm{ft}$ & $\leq 300 \mathrm{ft}$ \\
\hline \multirow{3}{*}{$\begin{array}{l}\text { Gold-Copper Por- } \\
\text { phyry }\end{array}$} & DHS & DHS & $\leq 50 \mathrm{~m}$ & $\leq 80 \mathrm{~m}$ \\
\hline & DNDH & $\leq 10 \mathrm{~m}-35 \mathrm{~m}, 50 \%-60 \%$ sill range & $\leq 40 \mathrm{~m}-50 \mathrm{~m}, 75-80 \%$ sill range & $\leq 50 \mathrm{~m}, 90 \%-100$ sill range \\
\hline & NDH & $\geq 1-\geq 3$ & $\geq 1-\geq 3$ & $\geq 1$ \\
\hline
\end{tabular}


Insights in Mining Science \& Technology

\begin{tabular}{|c|c|c|c|c|}
\hline & NS & $\geq 4$ & $\geq 4, \geq 8$ & $\geq 4-5$ \\
\hline & ES & $\leq 50 m-75 m$ & $\leq 70 m-100 m$ & \\
\hline \multirow{5}{*}{ Green-stone Belt } & DHS & $\leq 25 \mathrm{~m}$ & $\leq 25 \mathrm{~m}, 50 \mathrm{~m}$ & $\leq 100 \mathrm{~m}, 120 \mathrm{~m}$ \\
\hline & DNDH & $\leq 20$ & $\leq 20-30$ & \\
\hline & NDH & $\geq 2$ & $\geq 3$ & $\geq 2$ \\
\hline & NS & $\geq 16$ & $\geq 16$ & $\geq 8$ \\
\hline & ES & $\leq 50 \mathrm{ft}$ & $\leq 100 \mathrm{ft}$ & $\leq 500 \mathrm{ft}$ \\
\hline \multirow{4}{*}{ Lode and Placer } & DHS & & $40 \mathrm{~m} \times 40 \mathrm{~m}$ & $80 \mathrm{~m} \times 80 \mathrm{~m}$ \\
\hline & DNDH & $\leq 30.5 \mathrm{~m}, \leq 100 \mathrm{~m}$ & $\leq 61 \mathrm{~m}, \leq 36.6 \mathrm{~m}, \leq 200 \mathrm{~m}$ & $\leq 68.6 \mathrm{~m}, \leq 76 \mathrm{~m}, \leq 400 \mathrm{~m}$ \\
\hline & $\mathrm{NDH}$ & $\geq 3$ & $\geq 1-2$ & $\geq 1-2$ \\
\hline & NS & $\geq 3, \geq 6$ & $\geq 2, \geq 3$ & $\geq 3$ \\
\hline \multirow{5}{*}{ Mesozonal Orogenic } & DHS & & $\leq 25 \mathrm{~m}$ & $\leq 100 \mathrm{~m}$ \\
\hline & DNDH & $\leq 30 \mathrm{ft}, \leq 50 \mathrm{ft}$ & $\leq 75 \mathrm{ft}, \leq 100 \mathrm{ft}$ & \\
\hline & $\mathrm{NDH}$ & $\geq 1, \geq 3$ & $\geq 2$ & \\
\hline & NS & $\geq 6$ & $\geq 4$ & \\
\hline & ES & & $\leq 80 \%$ sill range & $\leq 90 \%$ sill range \\
\hline
\end{tabular}

\section{Discussion}

The research has shown that the gold mining industry players prefer the geometric method, since few reports applied geostatistical methods for classification. The geometric method is simple and faster to apply. Hence, there is the need to research into generation of an easier and timely geo-statistical classification framework to attract the interest of the gold industry players. A good and reliable resource estimation is important in the mineral extractive industry. During the survey, it was observed that different QPs applied different interpolation approaches on same type of de-posit. Different grade capping approaches were applied by different QPs. These included capping before compositing, capping after compositing, capping per geological domain, and average capping value for all geological domains. Each capping approach can lead to variation of the average grade of a deposit. Different block modeling approaches were identified in the survey. These included single block model for surface and underground operations of same deposit, multiple block models for surface and underground operations of same deposit, different block models for different geological domains, and same block model for different geological domains. Also, an estimation pass for mineral resource classification is very crucial in predicting blocks that belong to Measured, Indicated and Inferred categories. In the survey, different QPs from same mining company applied different assumptions for similar type of deposits. There was no consistency in the creation of the parameters used for estimation passes for classification.

\section{Conclusion}

The investigation has served as a basis for identifying how different Qualified Persons apply different assumptions and approaches to categorize mineral resources into measured, indicat- ed, and inferred in the gold mineral industry. The various mining companies considered in this survey did not apply consistent parameters for their estimation and classification methods for same type of deposit, as the individual resource estimator used different knowledge and experience to generate the classification requirements. This has proved that the industry lacks standard procedure to be followed by all QPs. Although, all the QPs followed the NI 43-101 guidelines, the different approaches used could result in misleading public reports, since there was no right or wrong approach until mining production period. In addition, a single judgement by a QP of a project has major influence on the prospect of economic extraction. This makes QPS assumptions play important role in determining the resource uncertainty associated with economic viability of deposits. To champion the cause of addressing the inconsistency and misclassification problems, the industry needs to investigate into acceptable limits for assumptions made by different QPs in the estimation and classification of mineral resources, particularly in terms of geology and deposit type.

\section{References}

1. Shaw WJ, Godoy MC, Muller G, Larrondo P (2006) An approach to more objective classification of mineral resources. $6^{\text {th }}$ International Mining Geology Conference, AusIMM NT pp. 85-89.

2. Deutsch CV, Leuangthong O, Ortiz JM (2016) A case for geometric criteria in resources and re-serve classification. CCG Annual Report 08: Paper 301.

3. Ortiz JM, Emery X (2006) Geostatistical estimation of mineral resources with soft boundaries: a comparative study. Journal of the South African Institute of Mining and Metallurgy (ISI) 106(8): 577-584.

4. Verly G, Postolski T, Parker HM (2014) Assessing uncertainty with drill hole spacing studies: applications to mineral resources. Orebody modelling and strategic mine planning symposium. Aus IMM Melbourne pp. 109-118. 


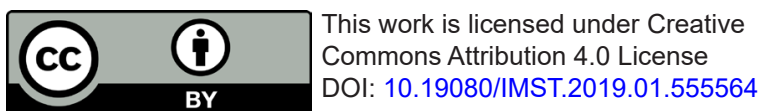

Your next submission with Juniper Publishers will reach you the below assets

- Quality Editorial service

- Swift Peer Review

- Reprints availability

- E-prints Service

- Manuscript Podcast for convenient understanding

- Global attainment for your research

- Manuscript accessibility in different formats

( Pdf, E-pub, Full Text, Audio)

- Unceasing customer service

Track the below URL for one-step submission https://juniperpublishers.com/online-submission.php 